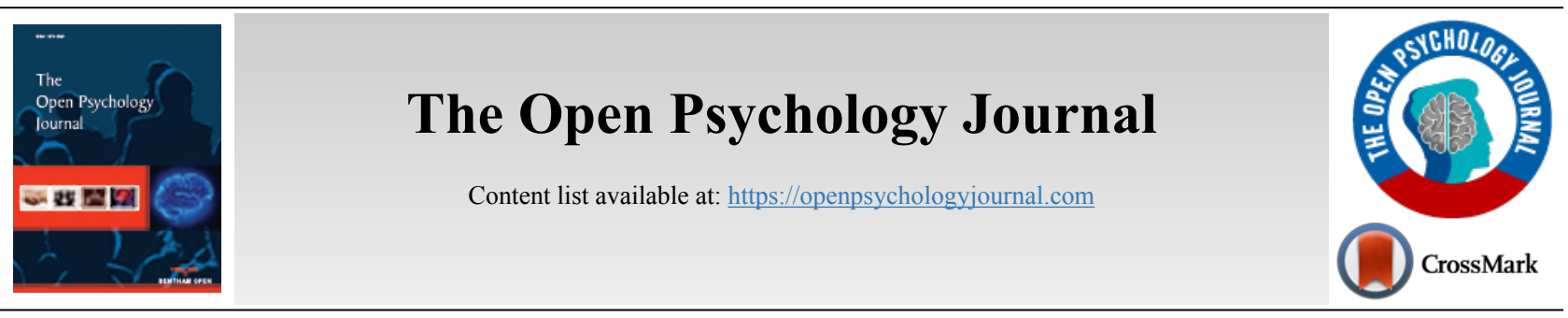

RESEARCH ARTICLE

\title{
Examining the Influence of Personality Traits and Family Income on Psychological Distress Among Farmers: The Role of Educational Status
}

\author{
Olabimpe A. Olatunji ${ }^{1, *}$, Erhabor S. Idemudia ${ }^{1}$ and Babatola D. Olawa ${ }^{2}$ \\ ${ }^{1}$ Faculty of Humanities, North-West University, Mafikeng Campus, Mafikeng, South Africa \\ ${ }^{2}$ Faculty of Health Sciences, North-West University, Mafikeng, South Africa
}

\begin{abstract}
:
Introduction:

Farming in most developing nations is still largely agrarian. Hence, ensuring high productivity among farmers requires that they must be both physically and psychologically healthy. The current study aimed at investigating the role of personality types and some demographic factors on psychological distress in farmers.

Methods:

The study employed a cross-sectional survey design of 301 farmers (male $=193$, female $=107$; age range $=17-74 ; \mathrm{M}=45.6 \mathrm{SD}=11.5)$ sampled purposively and conveniently from three major farm settlements in Ekiti State, Nigeria. Data were analyzed using multiple regression stratified by educational status.

Results:

Findings revealed that high neuroticism and low family income predicted psychological distress in less-educated farmers but not among more educated counterparts.

Conclusion:

Outcomes imply that less-educated farmers may be vulnerable to psychological distress due to personality disposition and economic factors. Increasing the level of literacy among farmers may wane the negative impact of neuroticism and low income on emotional wellness.
\end{abstract}

Keywords: Psychological distress, Farmers, Neuroticism, Educational level, Family income, Emotional wellness.

\begin{tabular}{|l|l|l|l}
\hline Article History & Received: August 21, 2020 & Revised: October 29, 2020 & Accepted: November 29, 2020
\end{tabular}

\section{INTRODUCTION}

Farming is a pivotal sector of any nation's economy, and remains central to economic development. About forty percent of the world's population is engaged in farming [1], while more than $60 \%$ depend on agriculture for their daily survival [2]. This makes the sector the largest provider of jobs worldwide. The agricultural sector employs about $36.38 \%$ percent of the Nigerian labor force and provides a daily livelihood for individuals residing in rural areas according to the World Bank Statistics [3]. Studies have shown that as developing countries undergo industrialization in other sectors,

\footnotetext{
* Address correspondence to this author at the Faculty of Humanities, NorthWest University, Mafikeng Campus, Mafikeng, South Africa; Tel: +27 837430112; E-mail: ajoke.olatunji@fuoye.edu.ng
}

the share of agriculture in Gross Domestic Product (GDP) declines, and this is usually accompanied by farmer's migration from agriculture to non-agriculture jobs [4]. This may be partly because farming is viewed as an occupation without dignity. In recent years, a considerable number of farmers have quit farming to take up "better" occupations with less strain and physical exhaustion [5]. However, the continuous migration of young men and families to the urban areas may cause a labor shortage for land preparation and harvesting. For an increase in per-worker productivity, there must be greater investments especially in the area of technologies, which will foster constant food supply to the nations [4].

Given that the agricultural system in Nigeria is highly less 
mechanized, heavy reliance on human labor may exhaust the personal resources and impact the general health of farmers. The system of farming is still largely agrarian and less mechanized to the extent that farmworkers do a lot of stooping, toiling, working with the soil, climbing, cultivating the soil, carrying heavy loads, harvesting, and directly handling the pesticides. All these problems put together may contribute to a lot of economic strain and physical exhaustion and invariably aggravates distress and eventually cause psychological distress in farmworkers. Psychological distress in farmers can be mild or chronic, and may manifest in loss of appetite, tiredness, irritability, weight loss, lack or less of concentration, sleeping problems, loss of self-esteem, substance abuse and some other symptoms have been reported [6].

Psychological distress is largely described as a state of emotional suffering and discomfort, which impacts one's level of functioning. Psychological distress in itself is a non-specific syndrome that covers symptoms such as depression, anxiety and stress [7]. It is widely used as a risk factor for poor mental health and is a major public health concern all over the globe [8]. Psychological distress is identified as one of the leading predisposing factors in the development of depression [9]. The prevalence is high among the general population in both developing and developed countries and depends on certain factors such as age, gender, job, personality traits and government policies for citizens [10].

The link between psychological distress and occupational stressors that are unique to farmers has been explicitly suggested in previous studies [11]. For example, in the $59^{\text {th }}$ round of the National Sample Survey (2003), it was revealed that over forty-eight percent of farmers are indebted, and about two-thirds of them are frustrated with their profession [12]. Farmers have significantly increased their debt profile by five percent annually in recent years [13]. Many of the challenges that accompany farming are concerned with financial issues, which cause a lot of distress in them, and this is usually a pointer to poor status [14]. Other challenges include lack of social support, which breeds social isolation [15], health challenges [16], climate variability [17], government policies and involvement [18] and several others.

Olowogbon et al. [18] reported that agricultural stressors which include poor harvest anxiety, labor scarcity, unfavorable government policies, poor transportation infrastructure, untimely access to farm inputs, poor market proximity, long hours of farm labor, poor access to credit facilities, poor access to market information, and long hours of labor affect farmers wellbeing in a sample of Nigerian farmers. Other studies identified physical exhaustion as a major stressor [19], while some other studies identified age, gender and level of education of individuals as contributing to the perception of stressors leading to psychological distress [20]. Studies also confirmed that farmers have poorer mental health than the general population, given their high level of economic and physical stress [18].

Past studies have identified personality factors and income as significant predictors of psychological distress in the general population. In a recent study conducted by Nouri et al. [21], they found that higher neuroticism predicts psychological distress and depression while participants with higher extraversion scores experienced lower levels of depression and lower risk of psychological distress though in a sample of the general population. Other studies confirmed the significant effect of personality on psychological distress among the general population [22]. Many studies have demonstrated the effect of family income on the psychological distress of the farmers' population. For example, Feng et al. [23] showed that family income significantly influenced psychological distress among farmers.

This study was premised on Social Cognitive Theory as posited by Bandura [24] where he suggested that personal and socio-environmental factors lead to health-compromising or health-enhancing behaviors, which in turn, affect mental health status. Bandura further explained that individual cognitive processes are important mediators of the connections between the environment and behavior. In this case, the level of education can act as cognition to mediate the personality behavior and family income of a farmer.

The current research is borne out of the fact that several studies have confirmed that personality accounts for a lot of variation in the mental health of humans, such as depression, loneliness and anxiety [25], and that personality influences various forms of psychological maladjustment [26]. Research also emphasizes the importance of education in mental health problems where higher education is linked with a low level of psychological distress [27]. However, it has also been demonstrated that high education may pose a significant risk to individuals' mental health [28].

\subsection{Aims and Hypotheses}

Based on the role of education in determining individual mental health level, the current study aims to examine whether the associations of personality and income with psychological distress varies among low and highly educated farmers. It is hypothesized that personality factors and family income will predict psychological distress differently among farmers with low and high education. The present study is significant, given that research examining the effect of personality factors and income on the level of psychological distress among farmers appears scanty and moreover, no study till date is yet to demonstrate whether the associations of personality and income with psychological distress vary among low and highly educated farmers conceptual framework (Fig. 1). 


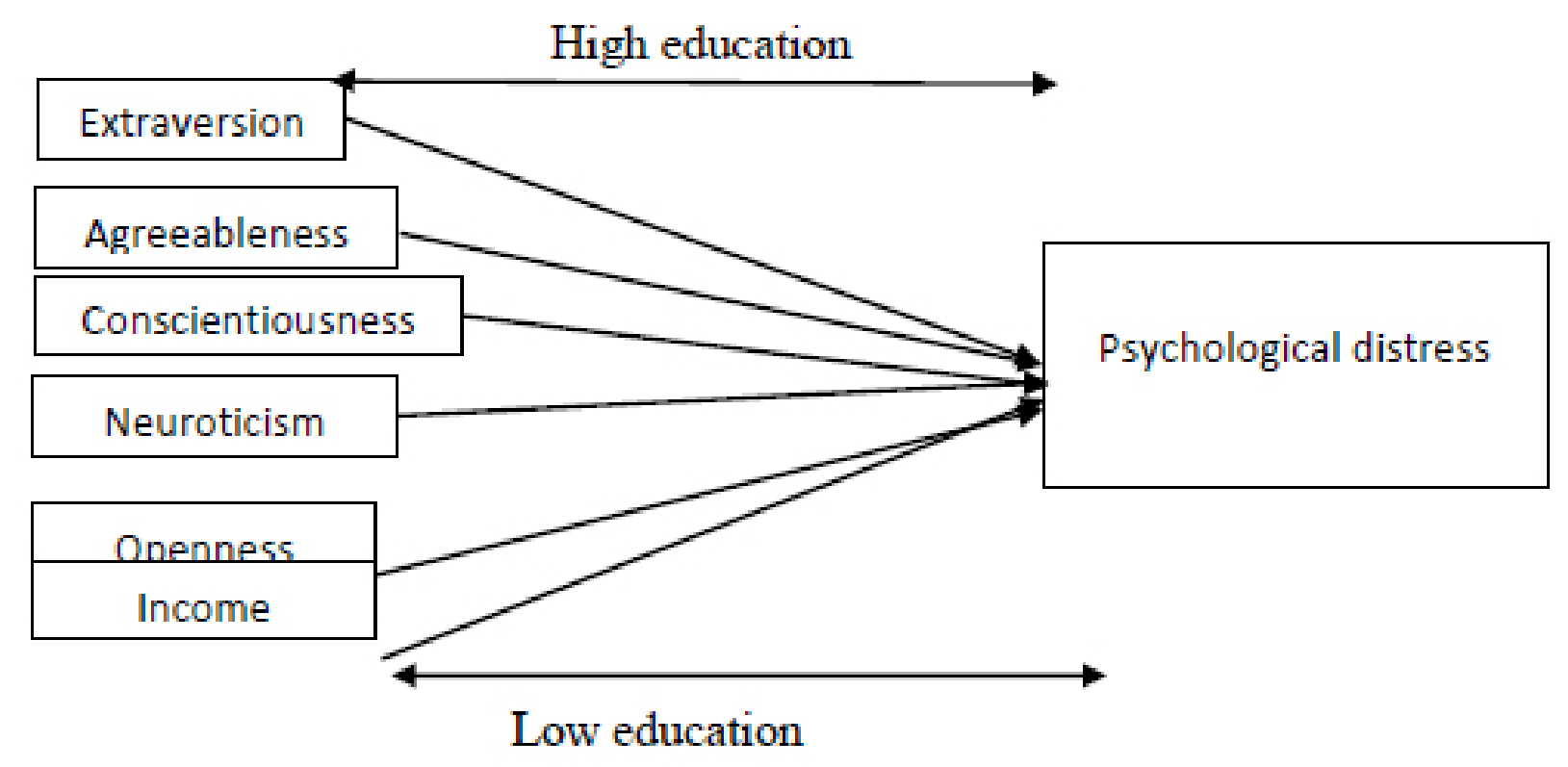

Fig. (1). Conceptual framework of the study stratified by educational status.

Note: Fig. 1 hypothesizes that personality factors and income will predict manifestation of psychological distress differently among low and highly educated farmers.

\section{METHODS}

\subsection{Samples and Procedure}

By utilizing a cross-sectional survey design, a total of 301 farmers were selected using snow-balling technique from the population of three major farm settlements in Ekiti State, Nigeria. The age range of the participants was 17years - 74 years $(M=45.5 ; \mathrm{SD}=11.5$; Male $=193$, Female $=107)$. Based on the level of family income distribution in naira, 117 (39\%) earns $10,000-49,999$ per month, $133(44 \%)=50,000-$ $99,999,45(15 \%)=100,000-499,999,4(1.3 \%)=500,000-$ 999,999 and $1(.3 \%)$ earns 1 million and above. Based on their educational level 44 (14.6\%) had no education, 128 (42.5\%) had Primary School certificate, 65 (21.6\%) had Secondary School certificate, $43(14.3 \%)$ had National Certificate Education / Ordinary National Diploma and 21 (7\%) had Higher National Diploma / B.Sc. certificate. According to their religiosity, $134(44.7 \%)$ were Muslims, 153 (51\%) were Christians while 13 (4.5\%) were Traditionalists. Based on their ethnicity classification, $228(76 \%)$ were Yoruba, 52 (17.3\%) were Igbo and $20(6.7 \%)$ were Hausa.

The ethics and research committee of the Department of Psychology of Federal University Oye-Ekiti granted approval for the conduct of the research. Verbal informed consent was obtained from kings and community heads in each of the communities, while informed consent was also obtained from individual participants before filling out the questionnaire. The farmers were approached after daily farming sessions in their various homes. After agreeing to participate in the study, consideration was made by the researchers to assist some of the participants who were either half illiterates or illiterates to help out in the reading out and interpreting some of the difficult items of the questionnaire.

\section{MEASURES}

\subsection{Socio-demographic Information}

\subsubsection{The Big Five Personality Inventory}

Personality was assessed using a 10-item Big Five Personality Inventory [29]. It is measured on a 5-point Likert scale ranging from Strongly Disagree (1) to Strongly Agree (5). Samples of scale items include "I see myself as someone who is reserved" and "I see myself as someone who is generally trusting". The 10 items of the scale assess five dimensions of the scale, which are openness $(5,10)$, conscientiousness $(3,8)$, agreeableness $(2,7)$, extraversion $(1,6)$ and neuroticism $(4,9)$. The scale has been used in several studies conducted using the Nigerian population, and it has been found to be reliable and valid [30].

\subsubsection{Psychological Distress Scale (K10 scale)}

Psychological distress was assessed using the Kessler Psychological Distress Scale [31]. It is a 10 item scale rated on a 5-point Likert scale ranging "none of the time (1)" to "all of the time (5) and designed to yield a global measure of distress based on questions about anxiety and depressive symptoms that a person has experienced within a month. Sample items include "During the last 1 month, about how often did you feel tired out for no good reason?" and "During the last 1 month, about how often did you feel nervous?". Authors reported .91 reliability coefficient. This current research obtained a reliability coefficient of .76 .

\subsubsection{Statistical Analysis}

Data were analyzed with the aid of the statistical package for Social Sciences software (SPSS) version 24.0. Frequency, mean and standard deviation scores were calculated using descriptive statistics. Bivariate relationships among study 
variables were established using Person's correlation. Multiple regression analysis was utilized to test the predictive ability of personality factors and income on psychological distress. Missing data were replaced with mean values because missing scores were not more than $15 \%$ of cases. Data distribution was moderately normal, given that skewness scores to range between -1 to +1 , as shown in preliminary data analyses (Table 1).

\section{RESULTS}

Table 2 presents the bivariate relationships among study variables stratified by education. Among farmers with lower education, psychological distress was found to be positively related with neuroticism $(\mathrm{r}=.28, \mathrm{p}<.001)$ and negatively associated with income $(r=-.27, p=.001)$. Specifically, lower income was associated with higher psychological distress. However, extraversion $(\mathrm{r}=-.02, \mathrm{p}=.77)$, agreeableness $(\mathrm{r}=$ $.15, \mathrm{p}=.053)$, conscientiousness $(\mathrm{r}=-.02, \mathrm{p}=.75)$ and openness $(\mathrm{r}=.03, \mathrm{p}=.68)$ were not related to psychological distress. In famers with higher educational level, all predictor variables including extraversion $(\mathrm{r}=.13, \mathrm{p}=.13)$, agreeableness $(\mathrm{r}=.02, \mathrm{p}=.84)$, conscientiousness $(\mathrm{r}=-.04, \mathrm{p}=$ $.65)$, neuroticism $(\mathrm{r}=.06, \mathrm{p}=.52)$, openness $(\mathrm{r}=-.11, \mathrm{p}=.23)$ and income $(\mathrm{r}=-.11, \mathrm{p}=.23)$ do not form significant relationship with psychological distress.

Table 3 shows the multiple regression results for psychological distress stratified by educational level. The combined influence of personality characteristics and income was significant on psychological distress $[F(6,164)=4.13, p$ $=.001]$ with a variance of $13 \%$ among farmers with no education/lower educational level. Independently, only neuroticism $(\beta=.26, p=.001)$ and income $(\beta=-.18, p=.02)$ were significant in the model. However, the combined and independent influence of personality characteristics and income were not significant in psychological distress $[\mathrm{F}(6,122)=.98$, $\left.\mathrm{p}=.44, \mathrm{R}^{2}=.05\right]$ among farmers with a higher level of education.

Table 1. Distribution of Social-demographics.

\begin{tabular}{|c|c|c|}
\hline $\mathbf{N}=\mathbf{3 0 0}$ & $\mathbf{n}$ & $\%$ \\
\hline Sex & - & - \\
\hline Male & 193 & 64.3 \\
\hline $\begin{array}{c}\text { Female } \\
\text { Age }\end{array}$ & 107 & 35.7 \\
\hline $26-36$ & 68 & 22.7 \\
\hline $37-47$ & 104 & 34.7 \\
\hline $48-58$ & 78 & 26 \\
\hline$>58$ & 50 & 16.7 \\
\hline Religious affiliation & - & - \\
\hline Christianity & 153 & 51 \\
\hline Islam & 134 & 44.7 \\
\hline Traditional & 13 & 4.3 \\
\hline Ethnicity & - & - \\
\hline Yoruba & 228 & 76 \\
\hline Igbo & 52 & 17.3 \\
\hline Hausa & 20 & 6.7 \\
\hline Family income (in Naira) & - & - \\
\hline $10,000-49,999$ & 117 & 39 \\
\hline $50,000-99,999$ & 133 & 44 \\
\hline $100,000-499,999$ & 45 & 15 \\
\hline $500,000-999,999$ & 4 & 1.3 \\
\hline 1 million $\&$ above & 1 & .3 \\
\hline
\end{tabular}

Table 2. Correlations among study variables stratified by lower (below the diagonal) and higher educational level (above the diagonal).

\begin{tabular}{|c|c|c|c|c|c|c|c|c|c|}
\hline & $\mathbf{1}$ & $\mathbf{2}$ & $\mathbf{3}$ & $\mathbf{4}$ & $\mathbf{5}$ & $\mathbf{6}$ & $\mathbf{7}$ & $\mathbf{8}$ & $\mathbf{9}$ \\
\hline Mean & & & 45.88 & 5.71 & 6.45 & 6.08 & 6.07 & 7.45 & 20.11 \\
\hline SD & & & 11.44 & 2.85 & 1.62 & 1.73 & 1.99 & 1.92 & 5.46 \\
\hline Sex (1) & & .06 & $-.32^{* *}$ & .03 & -.04 & .07 & .12 & -.12 & .17 \\
\hline Income (2) & -.05 & & .03 & .16 & -.01 & -.11 & -.16 & -.02 & -.01 \\
\hline Age (3) & -.12 & $.33^{* *}$ & & -.06 & .002 & -.06 & -.03 & -.02 & -.11 \\
\hline Extraversion (4) & .06 & -.03 & -.05 & & -.15 & -.09 & $-.21^{*}$ & $-.31^{* *}$ & .13 \\
\hline Agreeableness (5) & -.01 & .09 & -.08 & -.06 & & $.23^{*}$ & $.44^{* *}$ & $.20^{* *}$ & .02 \\
\hline
\end{tabular}


(Table D) contd.....

Table D contd....
\begin{tabular}{|c|c|c|c|c|c|c|c|c|c|}
\hline & $\mathbf{1}$ & $\mathbf{2}$ & $\mathbf{3}$ & $\mathbf{4}$ & $\mathbf{5}$ & $\mathbf{6}$ & $\mathbf{7}$ & $\mathbf{8}$ & $\mathbf{9}$ \\
\hline Conscientiousness (6) & -.06 & .07 & .05 & .09 & .02 & .02 & $.33^{* *}$ & .13 & -.04 \\
\hline Neuroticism (7) & -.01 & -.04 & $-.23 * *$ & .06 & $.17 *$ & $.21 * *$ & & $.22^{*}$ & .06 \\
\hline Openness (8) & .01 & .05 & -.11 & -.07 & -.03 & .12 & $.32^{* *}$ & & -.11 \\
\hline Psychological distress (9) & .03 & .02 & $-.24 * *$ & -.02 & .15 & -.02 & $.28 * *$ & .03 & \\
\hline
\end{tabular}

Sex $(0=$ male, $1=$ male $)$ Income $(0=$ lower income, higher income $) .{ }^{* *} \mathrm{p}<.01 ;{ }^{*} \mathrm{p}<.05$

Table 3. Regression model examining the predictors of psychological distress by educational level.

\begin{tabular}{|c|c|c|c|c|c|c|}
\hline \multirow{2}{*}{$\begin{array}{c}\text { Variables } \\
-\end{array}$} & \multicolumn{3}{|c|}{ No education/Lower education level } & \multicolumn{3}{|c|}{ Upper education level } \\
\hline & $\mathrm{B}$ & SEB & $\mathrm{B}$ & $\mathrm{B}$ & SEB & $\mathrm{B}$ \\
\hline Extraversion & -.10 & .17 & -.04 & .20 & .16 & .12 \\
\hline Agreeableness & .32 & .28 & .09 & .06 & .31 & .02 \\
\hline Conscientiousness & -.18 & .23 & -.06 & -.22 & .32 & -.07 \\
\hline Neuroticism & .74 & .23 & $.26 * *$ & .31 & .28 & .11 \\
\hline Openness & -.19 & .23 & -.07 & -.27 & .27 & -.09 \\
\hline Income & -1.96 & .83 & $-.18^{*}$ & -1.15 & 1.02 & -.10 \\
\hline $\mathrm{R}$ & - & .36 & - & - & .21 & - \\
\hline $\mathrm{R}^{2}$ & - & .13 & - & - & .05 & - \\
\hline $\mathrm{F}$ & - & $4.13 * *$ & - & - & .98 & - \\
\hline
\end{tabular}

\section{DISCUSSION}

Past studies have shown that personality factors and income levels are associated with psychological distress in the general population. However, we do not know whether these relationships are replicated in farmers and whether the associations in these variables are differed by educational level. The present study was undertaken to contribute to the literature by investigating how the association of personality factors and income levels with psychological distress differ by educational status. It was indicated from the findings of this study that the family income of the less educated farmers independently predicted their level of psychological distress. This is congruent with past and contemporary studies in this area that have consistently found a link between these two variables. For example, Sakurai et al. [32] found that low income predicted psychological distress among a sample of farmers in Japanese. Other studies reported similar findings [18, 33 - 35].

Our results also found that only neuroticism of all the five personality types had a significant independent prediction of psychological distress in farmers. Findings corroborate other studies suggesting that higher neuroticism increases the level of psychological distress in the general population [21, 22, 36]. Thus less educated farmers who are emotionally unstable have the tendency to be depressed and anxious. While this study found the combined influence of personality characteristics and income as significant on psychological distress, it was, however, interesting to find that this significance only occurred among farmers with lower educational status or no education at all. This further explains the importance of education, even among farmers. For example, Monden [37] found that highereducated men experience less psychological distress following job loss.

The theoretical implication of findings is that neuroticism and income may determine the manifestation of psychological distress in low educated farmers. It further implies, being uneducated or lowly educated may predispose farmers to mental health problems from neuroticism traits and low income. However, the impacts of neuroticism traits and low income may not be significant on mental health problems among highly educated farmers because higher education may contribute to the buffer against the negative effect of neuroticism and financial difficulties on mental health [27]. Higher education may propel one to new and diverse ideas on coping strategies against distress.

\section{LIMITATIONS AND SUGGESTIONS FOR FURTHER STUDIES}

Despite the usefulness of the findings and recommendations of this study, it is important to point its limitation. First, causal-effect relationships cannot be drawn among variables since the study design is cross-section and questionnaire-based. Future studies in this area may adopt a longitudinal framework to overcome this limitation. Second, our sample size $(\mathrm{n}=301)$ may be considered as low, considering the huge population of farmers in Nigeria. This may limit the generalizations of findings to the wider population of farmers. Prospective research may utilize a larger sample size to achieve better generalization of findings. Lastly, study findings may not apply to farmers in highly developed nations because farming in such societies is mechanized-based as compared to the crude method still common in less developed nations. Hence, this study should be replicated among farmers within developed nations to determine whether differences will exist in findings.

\section{CONCLUSION}

Summarily, it can be deduced from the current study that while neuroticism and family income level act as pointers to psychological distress in farmers, it only predicts psychological distress in farmers with low levels and no educational background. It is therefore recommended that government 
agencies in charge of agriculture should provide a centralized market (instead of individual sales) where prices for sales of farm produce can be fixed to reflect the efforts of the farmers. This is necessary because, from the observation of demographic distribution in the present study, the majority of the rural farmers are illiterate, the centralized market, therefore, will act as a control and check on the prices that retailers buy the farm produce from the farmers, this reduces the farmers' worry and distress, and it helps them to sell on the actual worth whereby both the farmers and the retailers who buy in bulk have shared gains. In addition, clinics that cater to both physical and psychological health challenges should be provided at or around major farm settlements. Farmers go through a lot of theft on farm produce, poor harvest anxiety, unavailability of materials and fund and a lot of emotional instabilities. It is, therefore important that mental health services should be readily available to farmers for improved psychological wellbeing and emotional wellness.

\section{ETHICS APPROVAL AND CONSENT TO PARTI- CIPATE}

The study was approved by the ethics and research committee of the Department of Psychology of Federal University Oye-Ekiti, Nigeria under approval no. PSY/EC/19/3571.

\section{HUMAN AND ANIMAL RIGHTS}

Not applicable.

\section{CONSENT FOR PUBLICATION}

The participants were informed of the objectives of the study and they completed the informed consent forms before the questionnaires were distributed to them. Utmost confidentiality of information were ensured.

\section{AVAILABILITY OF DATA AND MATERIALS}

The data and materials used to support the findings of this study are available from the corresponding author [OAO] upon reasonable request.

\section{FUNDING}

None.

\section{CONFLICT OF INTEREST}

The authors declare no conflict of interest, financial or otherwise.

\section{ACKNOWLDEGEMENTS}

Declared none.

\section{REFERENCES}

[1] Agricultural and Rural Development. 2014.World Bank Open Data

[2] Food and Agriculture Organization of the United Nations. Agriculture remains central to the world economy $60 \%$ of the population depends on Agriculture for survival. Economy 2013.

[3] World Bank Statistics (2019). Nigeria - Employment in Agriculture (\% of total employment).. Trading Economics com. 2019.

[4] Food and Agriculture Organization. The World Bank International Labor Organization Labor force total 2014. World Bank 2018.
[5] Chemonics International. Nigeria 2003.Nigeria food security assessment Final report USAID.

[6] Logstein B. Farm-related concerns and mental health status among Norwegian farmers. J Agromed 2016; 21(4): 316-26. [http://dx.doi.org/10.1080/1059924X.2016.1211055] [PMID: 27420178]

[7] Preville M, Boyer R, Potvin L, Perreauult C, Legare G. La detresse psychologique: Determination de la fiabilite et dela mesure utilisee dans l'enquete sante, Quebec. Montreal: Sante Quebec 1992.

[8] Newbury-Birch D, Kamali F. Psychological stress, anxiety, depression, job satisfaction, and personality characteristics in preregistration house officers. Postgrad Med J 2001; 77(904): 109-11. [http://dx.doi.org/10.1136/pmj.77.904.109] [PMID: 11161078]

[9] Markou A, Cryan JF. Stress, anxiety and depression: Toward new treatment strategies. Neuropharmacology 2012; 62(1): 1-2. [http://dx.doi.org/10.1016/j.neuropharm.2011.09.023] [PMID: 21983630]

[10] Esch T, Stefano GB, Fricchione GL, Benson H. Stress in cardiovascular diseases. Med Sci Monit 2002; 8(5): RA93-RA101. [PMID: 12011786]

[11] Kallioniemi Marja, Simola Ahti, Kinnunen Birgitta. Stress in Farm entrepreneurs In: LAngan-Fox, Janice \& Cooper, Cary. 1 ed. Cheltenham, UK and Northampton, MA, USA: Handbook of stressin the occupations 2011; pp. 385-406. [PMID: 10.4337/9780857931153 ]

[12] Deshpande RS, Prabhu N. Farmers' distress: Proof beyond Question. Econ Polit Wkly 2005; 40(40/45): 4663-5.

[13] Briggeman B C. Federal reserve Bank of Kansas city. 2010.Debt, Income, and Farm Financial Stress.

[14] Dixon J, Gulliver A, Gibbon D. Farming systems and poverty; improving farmers' livelihood in a changing world. 2014.

[15] McPhedran S, Leo D. Suicide among rural men; Are farmers more socially isolated? Int J Sociol Soc Policy 2013. [http://dx.doi.org/10.1108/IJSSP-03-2013-0038]

[16] Brew B, Inder K, Allen J, Thomas M, Kelly B. The health and wellbeing of Australian farmers: a longitudinal cohort study. BMC Public Health 2016; 16: 988.

[http://dx.doi.org/10.1186/s12889-016-3664-y] [PMID: 27634298]

[17] Daghagh Yazd S, Wheeler SA, Zuo A. Key risk factors affecting farmers' mental health. A systematic review. Int J Environ Res Public Health 2019; 16(23): 4849.

[http://dx.doi.org/10.3390/ijerph16234849] [PMID: 31810320]

[18] Olowogbon TS, Yoder AM, Fakayode SB, Falola AO. Agricultural stressors: identification, causes and perceived effects among Nigerian crop farmers. J Agromed 2019; 24(1): 46-55.

[http://dx.doi.org/10.1080/1059924X.2018.1538915] [PMID: 30345895]

[19] Katalin T. Economic aspects of an agricultural innovation-precision crop production. Applied studies in agribusiness and commerce 2012; 6: 51-7.

[20] Kane S. Factors linked to psychological distress. Psychcentral 2019.

[21] Nouri F, Feizi A, Afshar H, Keshtel A H, Adibi P. 2019; How fivefactor personality traits affect psychological distress and depression? Results from a large population-bases study. Psychological study 64(1): 59-69.

[22] Liu Y, Gillespie NA, Ye L, Zhu G, Duffy DL, Martin NG. The relationship between personality and somatic and psychological distress: A comparison of Chinese and Australian Adolescents. Behav Genet 2018; 48(4): 315-22.

[http://dx.doi.org/10.1007/s10519-018-9905-3] [PMID: 29872974]

[23] Feng D, Ji L, Xu L. Effect of subjective economic status on psychological distress among farmers and non-farmers of rural China. Aust J Rural Health 2015; 23(4): 215-20.

[http://dx.doi.org/10.1111/ajr.12187] [PMID: 25945684]

[24] Bandura A. Social foundations of thought and action: A social cognitive theory. Englewood Cliffs, NJ: Prentice-Hall 1986.

[25] Cheng H, Furnham A. Personality, peer relations, and self-confidence as predictors of happiness and loneliness. J Adolesc 2002; 25(3): 327-39.

[http://dx.doi.org/10.1006/jado.2002.0475] [PMID: 12128043]

[26] Kotov R, Gamez W, Schmidt F, Watson D. Linking "big” personality traits to anxiety, depressive, and substance use disorders: A metaanalysis. Psychol Bull 2010; 136(5): 768-821.

[http://dx.doi.org/10.1037/a0020327] [PMID: 20804236]

[27] Aye WT, Lien L, Stigum H, Win HH, Oo T, Bjertness E. The prevalence of mental distress and the association with education: A cross-sectional study of 18-49-year-old citizens of Yangon Region, 
Myanmar. BMC Public Health 2020; 20(1): 94. [http://dx.doi.org/10.1186/s12889-020-8209-8] [PMID: 31969142]

[28] Molarius A, Granström F. Educational differences in psychological distress? Results from a population-based sample of men and women in Sweden in 2012. BMJ Open 2018; 8(4)e 021007

[http://dx.doi.org/10.1136/bmjopen-2017-021007] [PMID: 29705766]

[29] Rammstedt B, John OP. The 10-item Big Five Inventory. Norm values and investigation of socio-demographic effects based on a German population representative sample. Eur J Psychol Assess 2007; 23(3): 193-201.

[http://dx.doi.org/10.1027/1015-5759.23.3.193]

[30] Olawa BD, Idemudia ES. Later-life satisfaction with adult children's achievements: Does parents' personality matter? Heliyon 2019; 5(9)e 02406

[http://dx.doi.org/10.1016/j.heliyon.2019.e02406] [PMID: 31535043]

[31] Kessler RC, Mroczek D. Ann Arbor (MI): Survey research center of the institute for social research. University of Michigan 2002.Final versions of our non-specific psychological distress scale.

[32] Sakurai K, Kawakami N, Yamaoka K, Ishikawa H, Hashimoto H. The impact of subjective and objective social status on psychological distress among men and women in Japan. Soc Sci Med 2010; 70(11): 1832-9. [http://dx.doi.org/10.1016/j.socscimed.2010.01.019]

[PMID: 20303205]

[33] Phelps C. Sheffield: health and safety laboratory. 2001.'Stress in North Yorkshire, WPS/01/06 Phase 1 report'.

[34] Hawton K, Fagg J, Simkin S, Harriss L, Malmberg A, Smith D. The geographical distribution of suicides in farmers in England and Wales. Soc Psychiatry Psychiatr Epidemiol 1999; 34(3): 122-7.

[http://dx.doi.org/10.1007/s001270050122] [PMID: 10327836]

[35] Deary J, Willock J, McGregor M. Stress in farming psychosomatic medicine 1997; 38: 300-14.

[http://dx.doi.org/10.1002/(SICI)1099-1700(199704)13:2<131::AID-S MI727>3.0.CO;2-T]

[36] He J, Fan X, Yan J, Huang F, Wu W, Cai Z. The relationship between neuroticism and night eating: Exploring the mediating roles of psychological distress and maladaptive coping. Psychol Health Med 2019; 24(1): 68-75.

[http://dx.doi.org/10.1080/13548506.2018.1488081]

[PMID: 29912574]

[37] Monden WS, Mandemakers JJ. Does the effect of job loss on psychological distress differ by educational level? Work Employ Soc 2013; 27(1): 73-93.

[http://dx.doi.org/10.1177/0950017012460312]

\section{(C) 2021 Olatunji et al.}

This is an open access article distributed under the terms of the Creative Commons Attribution 4.0 International Public License (CC-BY 4.0), a copy of which is available at: (https://creativecommons.org/licenses/by/4.0/legalcode). This license permits unrestricted use, distribution, and reproduction in any medium, provided the original author and source are credited. 